\title{
Interpretación de algunos tratados relacionados con las dos primeras guerras macedónicas ${ }^{1}$
}

\author{
Interpretation of Some Treaties \\ Related to the First Two \\ Macedonian Wars
}

\author{
Ricardo Martínez Lacy \\ Instituto de Investigaciones Filológicas \\ Universidad Nacional Autónoma de México \\ lacy@unam.mx
}

Resumen: Generalmente se interpreta la expansión romana desde el punto de vista de Roma misma. Es posible proponer interpretaciones alternativas. Entre los testimonios legitimadores de las conquistas una especie importante son los tratados internacionales. Se presenta un análisis de los tratados entre Aníbal y Filipo V, entre Roma y la Confederación Etolia y entre Macedonia y el reino seléucida contra Ptolomeo V Epifanes.

Palabras clave: Imperialismo, diplomacia, interpretación, mundo helenístico.

Abstract: $\quad$ Roman expansion is generally interpreted from the Roman point of view. It is possible to attempt alternative interpretations. Among the legitimating testimonies of conquests are international treaties. Here is an analysis of the treaties between Hannibal and Philip V, between Rome and the Aetolian Confederacy and between Macedonia and the Seleucid kingdom against Ptolomy V Epiphanes.

Keywords: Imperialism, diplomacy, interpretation, Hellenistic world.

Recibido: $\quad 14$ de marzo de 2019

Aceptado: $\quad 3$ de mayo de 2019

${ }^{1}$ Agradezco los consejos de César Sierra Martín. 
Una supuesta imparcialidad ha llevado a los historiadores modernos de la conquista romana de Grecia a presentar este proceso desde un punto de vista favorable a Roma, pues, como consecuencia de ella, solo se ha conservado la versión romana. Parte importante de la construcción de la legitimidad de esta conquista son los tratados entre los Estados participantes y es notable que muchos aún se conservan, aunque sea en paráfrasis. ${ }^{2}$ A continuación presentaré el análisis de tres de ellos, explorando sobre todo su dimensión ideológica.

Testigo del proceso de conexión del mundo mediterráneo por obra de Roma, Polibio lo llamó symploké (entretejimiento). Parte muy importante de este fenómeno fue la conquista de Grecia por Roma. Desde la época arcaica Grecia había sobrepasado la cuenca del Egeo y se había extendido por todo el Mediterráneo y el Mar Negro, como ranas alrededor de un lago, para seguir la comparación de Platón. ${ }^{3}$ Sin embargo, la expansión de Roma en Magna Grecia y Sicilia no fue más que una extensión y consecuencia de la conquista de Italia.

Roma cruzó primero el Adriático para combatir a los ilirios y su primera intervención en Grecia fue la Primera Guerra Macedónica (214-205 ), ${ }^{4}$ peleada supuestamente para impedir la intervención macedonia al lado de Aníbal, que había invadido Italia y de quien se decía se había aliado con el rey macedonio Filipo V. La Segunda Guerra Macedonia se hizo con el pretexto de defender los intereses de aliados griegos de Roma y resultó en el confinamiento de Macedonia a sus territorios primigenios y la independencia de los Estados griegos (200-197). La Guerra Siria (195-189) resultó en la pérdida de toda Anatolia para el reino de los Seléucidas, así como de su flota y la imposición de una indemnización de 15000 talentos. Como resultado de la Tercera Guerra Macedonia (171-167), Roma creó cuatro repúblicas y, después de la derrota del rebelde Andrisco, fundó la provincia de Macedonia en 148. En 146 y 145 Roma destruyó la Confederación Aquea; no volvió a intervenir en Oriente hasta la Guerras Mitridáticas (88-84 y 73-67), pero en 133 aceptó en herencia el reino de Pérgamo en el que erigió la provincia de Asia. Siria fue convertida en provincia en el año 64. Egipto corrió la misma suerte después de una guerra civil con intervención de Egipto entre Octavio, por una parte y, Marco Antonio y Cleopatra, por la otra, conflicto que culminó en el año 30. La conquista de Grecia duró, pues, 170 años (de 200 a 30) y fue un proceso complejo que puede describirse como la alianza entre el Estado romano y las clases gober-

2 La recopilación más asequible es la de Schmitt, 1969.

3 Phaed. 109b.

4 Todas las fechas son antes de Cristo, a menos que se indique lo contrario. 
nantes griegas. Su resultado fue un imperio grecorromano que duraría un milenio y medio hasta la caída de Constantinopla bajo Mohamed II en 1453 d.C. 5

La historia la hacen los vencedores y hasta la fecha Roma ha tenido quién la defienda siempre. Así, Arthur Eckstein (2008) presenta a los romanos como los competidores exitosos en un juego implacable de guerras y anexiones. ${ }^{6}$ Para Paul Burton (2011), en cambio, los romanos eran los campeones de la amistad, en defensa de la cual se hicieron de un imperio. Solo William Harris (1979) aparece como alguien que aprecia la agresividad de los romanos que, si no era diferente de las de los Estados helenísticos u otros, sí era más eficaz precisamente por su cooptación de las élites extranjeras que adquirían la ciudadanía romana o latina.

Pero, a pesar de la naturaleza filorromana de las fuentes, es posible elaborar una versión antirromana. Se puede aducir el ejemplo de la Guerra Aquea (147-146). A principios del siglo xx la mayoría de los historiadores, a su vez alemanes, la vieron como una revolución social y execraron de ella. ${ }^{7}$ En 1970, Alexander Fuks la interpretó como una guerra más en la que los aqueos tomaron medidas de emergencia para enfrentar un enemigo mucho más poderoso. En 1979, Harris la presenta como un episodio más en el curso expansionista romano. En 1995 yo mismo la excluí de las rebeliones populares helenísticas y denuncié la narración polibiana como falsa (Martínez Lacy 1995: 17-29). Finalmente, en 1998, John Thornton hace una disección rigurosa y detallada del texto de Polibio para mostrar, en toda su parcialidad, la deformación histórica del megalopolitano (Thornton 1998).

Conviene comenzar por el tratado de alianza entre Aníbal y Filipo V de 215, que llevará a la Primera Guerra Macedónica. En ese momento Aníbal había vencido en la batalla de Cannas y ocupaba parte de Italia. Parecía que iba a salir victorioso de la Segunda Guerra Púnica, que si así hubiera sido, la guerra se llamaría Segunda Guerra Romana. Por su parte, Filipo había derrotado a los etolios y establecido una nueva confederación de aliados griegos siguiendo la línea fundada por Filipo II con la Liga de Corinto. La coyuntura era favorable para ambos y a los dos les convenía aliarse contra Roma.

5 Sobre esto, es cómodo consultar la obra editada por Nicolet 1977, de la que hay una traducción al español publicada en Barcelona por Labor. También es muy útil la obra de Harris 1979, de la que hay una traducción al español publicada en Barcelona por Península. También aconsejable es Schiavone 1990.

6 Por dar el ejemplo más reciente.

7 Puede verse un panorama general en las primeras ocho notas de Fuks (1970). 
Este es el texto del tratado que firmaron entonces, según Polibio:

1 Juramento que prestó Anibal el estratego, Magón, Mircano, Barmócaro y todos los senadores cartagineses que estaban con él y todos los cartagineses que peleaban con él ante Jenófanes de Atenas, hijo de Cleómaco, embajador a quien envió ante nosotros Filipo el rey, hijo de Demetrio, en nombre de sí mismo, de los macedonios y de sus aliados, 2 por Zeus, Hera y Apolo, por el dios protector de los cartagineses y por Hércules y Yolao, por Ares, Tritón y Poseidón, por los dioses de los que pelean conjuntamente y por Helios, Selene y Gea y por los ríos, los demonios y los mares, 3 por todos los dioses que poseen Cartago, por todos los dioses que poseen tanto Macedonia como el resto de Grecia, por todos los dioses del ejército y de cuantos sancionan este juramento. 4 Aníbal el estratego dijo, y todos los senadores cartagineses con él y todos los cartagineses que peleaban con él, respecto a lo que parezca bueno a ustedes y a nosotros, prestar este juramento de amistad y genuina buena voluntad, como amigos, familiares y hermanos, $\mathbf{5}$ bajo las cláusulas siguientes: serán cuidados por el rey Filipo y los macedonios y por los otros griegos todos los que son sus aliados, los cartagineses soberanos y Aníbal el estratego y los que lo acompañan y los súbditos cartagineses y todos cuantos siguen sus leyes, y los uticenses y cuantas polis y pueblos estén sujetos a Cartago, y los soldados y los aliados, 6 y todas las polis y pueblos con las que hay por nosotros amistad en Italia, en Galia y en Liguria y los que pacten con nosotros amistad y alianza en ese país. 7 Y también el rey Filipo y los macedonios y los otros aliados griegos sean salvados y cuidados por los cartagineses que pelean con ellos y por los uticenses y por todas las polis y pueblos que están sujetos a los cartagineses, y los aliados y soldados y por todos los pueblos y polis que están en Italia, y en Galia y Liguria y por todos los otros que se vuelvan aliados en estos lugares de Italia. 8 No intrigaremos entre nosotros ni recurriremos al disimulo entre nosotros, estaremos con toda buena disposición y voluntad sin dolo ni intriga y seremos enemigos de los que combatan a los cartagineses con excepción de los reyes y las polis y los pueblos con los cuales tenemos juramentos y amistades. 9 Y nosotros también seremos enemigos de los que combaten contra el rey Filipo, con excepción de los reyes, las polis y los puertos con los cuales tenemos juramentos y amistades. 10 Sean también nuestros <aliados> para la guerra que tenemos contra los romanos hasta que los dioses nos den y les den la victoria. 11 Ustedes nos ayudarán según haya necesidad y según acordemos. 12 Que los dioses nos den victoria (?) en la guerra contra los romanos y sus aliados, y si los romanos pidieran pactar amis- 
tad, pactaremos, de modo que haya la misma amistad con ustedes, 13 bajo las cláusulas siguientes: no se les permitirá a ellos declararles la guerra en ningún momento, ni que los romanos sean dueños de Corcira, ni de Apolonia ni de Epidamno, ni de Faro, ni de Dimalis y Partino, ni de Atintania. 14 Y entregarán a Demetrio de Faros todos sus súbditos que están en poder de los romanos. 15 Y si los romanos inician una guerra contra ustedes o contra nosotros, nos ayudaremos mutuamente en la guerra según la necesidad de cada uno. 16 E igualmente si algunos otros con excepción de los reyes, las polis y los pueblos con quienes hay juramentos y amistad. 17 Y si parece necesario eliminar o añadir algo a este juramento, anularemos y agregaremos como a nosotros dos nos parezca (Polibio 7.9.1. Traducción mía).

Hay que comparar esto con lo que dice Tito Livio:

9 Jenófanes llegó hasta la Campania cruzando las posiciones romanas, y desde allí, por el camino más corto, hasta el campamento de Aníbal, ajustando con él un tratado de amistad en los siguientes términos: 10 el rey Filipo con la flota más grande que le fuera posible - y parecía estar en condiciones de reunir doscientas naves - pasaría a Italia, devastaría la costa y haría por su propia cuenta la guerra por tierra y por mar; 11 finalizada la guerra, Italia entera, incluida la propia ciudad de Roma, pasaría a poder de Aníbal y los cartagineses y el botín le sería cedido a Aníbal en su totalidad; 12 sometida Italia por completo, los cartagineses zarparían para Grecia y harían la guerra contra quienes quisiere el rey; las ciudades del continente y las islas del contorno de Macedonia serían para Filipo y su reino (Livio 23.33. Traducción de José Antonio Villar Vidal).

Y añade:

34.1 Tales fueron, aproximadamente, los términos del acuerdo suscrito entre el general cartaginés y los diputados de los macedonios; estos, acompañados de Gisgón, Bostar y Magón, enviados como comisionados para recibir del propio rey la confirmación del compromiso, llegaron hasta las inmediaciones del santuario de Juno Lacinia, al sitio donde se encontraba la nave oculta en un fondeadero.

A continuación, cuenta Livio que Jenófanes y sus compañeros cartagineses fueron interceptados en el mar por Valerio Flaco y descubiertos, después de lo cual fueron enviados prisioneros a Roma (Livio 23.34.2-9). 
Elias Bickerman, en un artículo publicado en 1952, muestra las semejanzas y diferencias con tratados fenicios y de otras culturas de Asia occidental, con referencia a siglos anteriores. Sin embargo, por el testimonio de Livio, todo indica que el tratado no llegó a su destino y que Polibio lo pudo consultar en Roma, como los tres tratados entre Roma y Cartago que transcribe en su tercer libro (Livio 3.22-25). ${ }^{8}$ Es posible que Aníbal enviara otra embajada a Macedonia, a pesar del dominio que Roma obviamente ejercía sobre los mares, pero también podría tratarse de una falsificación de alguien que conociera los tratados púnicos y los haya imitado. La suposición se confirma si uno se pregunta por qué envió Filipo una embajada a Aníbal en Italia, que era el capitán de la guerra contra Roma, y no directamente a Cartago, para pactar de gobierno a gobierno. El supuesto tratado prácticamente no tuvo ningún efecto: Filipo no pasó a Italia y Aníbal casi no lo pudo ayudar. Además, Jenófanes, aunque nombrado también por Livio y Apiano (Mac. 1.2), no aparece más en la historia. El texto de este tratado, sobre todo en la versión de Livio, escrito dos siglos después de los sucesos, justifica plenamente el tratado entre Roma y la Confederación Etolia en contra de Filipo y le quita el carácter de guerra preventiva que tendría de otra manera.

A continuación, presento el texto del tratado entre Roma y Etolia. Está consignado por Tito Livio (36.24), pero en 1954 Gunther Klaffenbach publicó una inscripción incompleta en su parte superior que registra otra versión, la cual traduzco:

[...] se vuelvan o ... [en] lo que toca a todos ellos [... los ma]gistrados de los etolio[s ha]ga[n] como se quiere, se haga. Y si los romanos tomaran por la fuerza algunas polis de estos pueblos, que sea lícito que estas polis y sus [c]ampos por iniciativa de los romanos los tenga el pueblo de los etolios; y lo que los romanos tomen fuera de las ciudades o los campos, lo tengan los romanos. Y si los romanos y los etolios tomaran en común algunas de estas polis, por iniciativa del pueblo —romano-, sea lícito que estas ciudades y campos los tengan los etolios. Y si ambos tomaran en común algo fuera de las ciudades o los campos sea de los dos. Y si algunas de estas polis se acercaran o se unieran a los romanos o a los etolios, por iniciativa del pueblo romano, [sea lícito] que estos

8 Aunque es de suponer que no estaban en el mismo lugar, puesto que los tratados romano-cartagineses se conservaban en inscripciones de piedra, y este tratado estaba escrito en un papiro. 
hombres y las polis y los campos los incorporen a la confederación de los etolios (Moretti 1967-1975: núm. 87).

Siguen tres renglones con muchos huecos que no tiene sentido intentar traducir.

La versión de Livio es muy resumida (traducción, con correcciones, de Fernando Gascó y José Solís):

8 ... Así pues, fueron redactadas las condiciones por las que entrarían en amistad y alianza con el pueblo romano, 9 llevando anejas las disposiciones siguientes: que, siempre por decisión y voluntad propias, podrían estar en el mismo pacto de amistad los elitanos, los lacedemonios, Atalo, Pléurato y Escerdiledas, Atalo rey de Pérgamo, aquellos de los tracios y de los ilirios; 10 que los ilirios emprenderían por tierra las hostilidades contra Filipo inmediatamente; que el general romano colaboraría con no menos de 25 navíos quinquerremes; 11 que pasarían a poder de los etolios el suelo, los edificios, los muros y el territorio de las ciudades hasta Corcira, todo el resto del botín sería del pueblo romano; y que los romanos prestarían su ayuda para que los etolios ocuparan Acarnania; 12 que, si los etolios hacían la paz con el rey Filipo, deberían adjuntar al tratado que la paz sería ratificada si Filipo renunciaba a la guerra contra los romanos, sus aliados y los que estuviesen bajo la jurisdicción de estos; 13 igualmente, si el pueblo romano firmaba un tratado con el rey, pondrían cuidado en despojar al rey del derecho de declarar la guerra a los etolios y a sus aliados (Livio 26.24).

La existencia de la inscripción es prueba de la autenticidad del tratado y muestra cómo Livio lo resumió.

Acerca de este tratado se pueden hacer las siguientes consideraciones. En primer lugar, Filipo no tenía ninguna flota para cruzar el Adriático y toda la guerra se dio en Grecia. Livio menciona la presencia ahí de una flota púnica de tamaño indeterminado (Livio 28.7.17-18.). Con ello y unos refuerzos aqueos, Filipo desembarcó en la etolia Erutras y saqueó ganado de su campo (Livio 28.8.9). Acerca de los contingentes romanos solo se sabe que al final de la guerra llevaron a Grecia 10 ooo infantes, 1000 jinetes y 35 naves cuando la guerra contra Aníbal aún no acababa.

Más sorprendente parece el tratado entre Macedonia y Siria contra Egipto. Vale la pena citar a Polibio: 
¿Quién no se extrañaría de lo siguiente? Cuando el mismo Ptolomeo [IV] vivía, no necesitaba la ayuda de estos [sc. Filipo V y Antíoco III], pero ellos estaban dispuestos a asistirle; 2 en cambio, cuando él falleció, dejando un niñito huérfano, a quien por naturaleza tocaba contribuir en salvar su trono, entonces se animaron el uno al otro y se dispusieron a repartirse el imperio del niño y matar al abandonado, 3 y ni siquiera, como los tiranos, adujeron algún somero pretexto para paliar su vergüenza, sino [que lo hicieron] de inmediato, licenciosa y bestialmente, de modo que incurrieron en lo dicho sobre la vida de los pescados, según el cual, aunque sean de la misma especie, la destrucción de los menores se convierte en nutrición y vida para los mayores. 4 Así, ¿quién que no podría ver como testigo en un espejo creería ser esto un atentado para con los dioses y una crueldad para los hombres y, aún más, una ambición excesiva de los reyes mencionados? 5 Pero también, ¿quién que culparía con razón a la fortuna sobre las cosas humanas no se reconciliaría en estos casos, que les asignó después de esto el castigo correspondiente, a los que a continuación puso un óptimo ejemplo para el castigo del descaro de los reyes mencionados? 6 Pues aun rompiendo su tratado entre ellos de desbaratar el dominio del niño, les puso a los romanos, y lo que ellos planeaban ilegítimamente contra los vecinos, eso mismo se dictaminó contra ellos justa y apropiadamente (Polibio 15.20. Traducción mía).

Sorprende el tono y el contenido: Polibio está presentando a Roma como el ejecutor de la fortuna justiciera. Los tres reyes en cuestión son tratados como particulares miembros de una sola especie y no como jefes de Estado con todo un aparato, de los cuales el Estado egipcio era precisamente el más complejo. ¿Qué alianzas se supone que rompieron traidoramente Antíoco y Filipo y por qué Polibio no las menciona explícitamente?

Asombra más aún el tratamiento que le han dado los historiadores modernos. Son pocos los que han dudado de su existencia (Magie 1939; de Regibus 1952; Baldson 1954, y Errington 1971), mientras que otros de la talla de Frank Walbank y Edouard Will creen que se pactó y por lo tanto suponen que los reyes helenísticos no pensaban como reyes sino como jefes de pandilla callejera y que los reyes adultos creían que Ptolomeo V estaba indefenso solo por ser un niño huérfano, como si no tuviera regentes, cortesanos, amigos, soldados, generales, todo un aparato estatal y un reino con millones de súbditos (Walbank 1957-1979, II: 471-474; Will 1979-1982, II: 114-118). Pero el que más crédito le da es Arthur Eckstein, que lo usa para mostrar cómo los romanos se ocupaban de imponer el orden internacional en oposición a la anar- 
quía que promovían los Estados helenísticos (Eckstein 2008: 121-180). ¡Las polémicas de hace 2200 años siguen vigentes, y Roma todavía necesita que la defiendan! El tono mismo de Polibio lo delata. Su parcialidad por Roma es explícita. ¿Acaso los historiadores modernos todavía tienen fe en la Týche y en la legitimidad del Imperio romano?9

Otro asunto es la publicidad del tratado. Polibio dice que los reyes se jactaban de él, lo cual solo hubiera sido posible si hubieran difundido el tratado, cosa que parece increíble. Tanto que, los que aceptan su existencia plantean también su índole secreta, pero no explican cómo se descubrió y contradicen el testimonio de Polibio sin siquiera aducir razones. Al parecer, esta interpretación tiene su origen en Maurice Holleaux, aunque no cita ninguna fuente ni presenta ningún argumento para darlo por auténtico (Holleaux [s. a.]; el prólogo está fechado en 1920).

En conclusión, hay que decir que los tratados internacionales de la Antigüedad (y me pregunto si es el caso también de los actuales) no solo representan un pacto entre varios estados, sino que también cumplen una tarea ideológica y justificatoria. En el caso del tratado entre Antíoco y Filipo, su invención permite a Polibio dar un giro moralista y metahistórico a la ruina de los reinos helenísticos, a los que obviamente detestaba. Pero lo más sorprendente es que los historiadores contemporáneos se siguen preocupando por la legitimidad de un Estado que dejó de existir hace siglos. Benjamin tenía razón: las clases dominantes actuales se identifican con las del pasado.

\section{Bibliografía}

Baldson, John Percy Vyvian Dacre (1954). "Rome and Macedon 205-20o B. C., Journal of Roman Studies, 44: 30-42.

Bickerman, Elias (1952). "Hannibal's covenant”, American Journal of Philology, 73: 1-23; ahora en Religion and politics in the Hellenistic and Roman periods, Emilio Gabba y Morton Smith (ed.), Edizioni New Press, 1985: 373-397.

Burton, Paul J. (2011). Friendship and diplomacy and imperialism in the middle republic (353-146 B.C.), Cambridge, Cambridge University Press.

9 Curiosamente, en su tesis de licenciatura, Vaidyanathan (2018: 65-67) considera la posibilidad de la inexistencia del tratado, pero afirma que lo contrario refuerza las condiciones en que se dio la expansión de Roma y explica por qué las embajadas de Pérgamo y Rodas acudieron a solicitar la ayuda de Roma, lo cual desató la Segunda Guerra Macedonia. No dice, sin embargo, cómo hicieron Rodas y Pérgamo para enterarse de un tratado que él plantea que fue secreto, en contra del testimonio explícito de Polibio. 
DE Regibus, Luca (1952). “Tolomeo V Epifane e l'intervento romano nel Mediterraneo orientale”, Aegyptus, 32: 97-100.

EcKSTEIN, Arthur M. (2008). Rome enters the Greek East. From anarchy to hierarchy in the Hellenistic Mediterranean 230-170 B.C., Malden, Blackwell Publishing.

ERrington, Robert Malcolm (1971). "The alleged Syro-Macedonian pact and the origins of the Second Macedonian War”, Athenaeum, 59: 336-354.

Fuks, Alexander, (1970). "The Bellum Achaicum and its social aspect ", Journal of Hellenic Studies, 90: 78-89

HARRIS, William Vernon (1979). War and imperialism in republican Rome, Oxford, Clarendon Paperbacks.

Holleaux, Maurice (s. a.). Rome, la Grèce et les monarchies hellénistiques au III siècle avant J.C., Paris.

Magie, David (1939). “The 'agreement' between Philip V and Antiochus III for the partition of the Egyptian Empire”, Journal of Roman Studies, 29: 32-44

MARTÍnEz LACY, Ricardo (1995). Rebeliones populares en la Grecia helenística, México, Universidad Nacional Autónoma de México.

MoretTI, Luigi. (1967-1975). Iscrizioni storiche ellenistiche. Testo criticvo, traducione e commento, 2 vols., Firenze.

NicOlET, Claude (ed.) (1977). Rome et la conquête du monde méditerranéen 264-27avant J.-C., Paris.

Schiavone, Aldo (1990). Storia di Roma, II-1. L'impero mediterraneo,Torino, Guilio Einaud Editore.

Schмiтт, Hatto H. (1969). Die Staatsverträge des Altertums. Band II: Die Verträge des grischischen-römischen Welt von 338 bis 200 v. Chr., München.

Thornton, John (1998). “Tra politica e storia: Polibio e la guerra acaica”, Mediterraneo Antico, 1 (2): 583-634.

Vaidyanathan, Vijay (2018). From Pyrrhus to Pydna. Roman imperialism in the Hellenistic Mediterranean 280-168 B.C., Newport.

Walbank, Frank William (1957-1979). A historical commentary on Polybius, 3 vols., Oxford.

WiLL, Édouard (1979-1982). Histoire politique du monde hellénistique, 2 vols., 2ª ed., Nancy.

\section{Ricardo Martínez Lacy}

Licenciado en historia por la UNAM; doctor en historia antigua por la Facultad de Estudios Clásicos de la Universidad de Cambridge. Ha publicado, entre otros, los libros: ¿En busca del tiempo perdido? (2016) y Diez inscripciones helenísticas sobre los ejércitos y la guerra (2008); como editor, Hermenéutica de la esclavitud (2018); diferentes capítulos de libros y aproximadamente 6o artículos. Ha impartido clases en la UNAM; en la Universidad Michoacana de San Nicolás, en Morelia; en la Universidad Westfálica Guillermo de Münster, en Alemania, y en la Universidad Autónoma de Barcelona. 